\title{
De la hermenéutica reflexiva a la hermenéutica practica para pensar y sentir desde mi historia en los espacios de formación docente
}

\section{(From reflexive to practical hermeneutics to think and feel on the basis of my experience within teacher training environments)}

\author{
*Bianney Xiomara Cedeño de Sánchez \\ Universidad de Oriente, Núcleo de Sucre -Venezuela \\ *Email de correspondencia: cedeno.bianney@hotmail.com
}

\section{RESUMEN}

La naturaleza de la investigación refiere a la hermenéutica integrada al conocimiento para potenciar el componente dimensional de lo humano. Me posicioné de un horizonte hermenéutico-comprensivo para interpretar la acción del docente y los significados que da a su quehacer educativo. Además, traduje una entrevista abierta y un diario de participantes aplicados a los actores principales de la investigación. La traducción de estas fuentes, permitió su organización en una red conceptual constituida por unidades de investigación, categorías, tipologías y conceptos integradores para configurar una teoría germinada partir de la interpretación del ser y hacer docente, desde sus prácticas vividas y sentidas. Los resultados obtenidos revelan como uno de los principales hallazgos, la existencia en los docentes de un pensamiento sensible disociado de una práctica y una teoría que define epistemológicamente el saber en los procesos de formación docente.

Palabras clave: hermenéutica; formación docente; prácticas vividas.

\begin{abstract}
The nature of the investigation describes the hermeneutics as integrated to knowledge to potentiate the human dimensional component. I took up a stance in a hermeneutics-comprehensive horizon to interpret the teacher's performance and the meanings he gives to his teaching practice. In addition, I translated an open interview and a participant journal that was applied to the main actors of the investigation. The translation of these sources allowed for their organization in a conceptual network constituted by investigation units, categories, typologies, and integrated concepts to configure a theory
\end{abstract}


elaborated from the interpretation of the teacher training and practice, based on his lived and felt experiences. The results obtained revealed, as one of its main findings, the existence of a sensible thinking in teachers. This thinking is dissociated from a practice and a theory that epistemologically defines knowledge in the teacher formation processes.

Keywords: hermeneutics; teacher formation; lived experiences. 


\section{INTRODUCCION}

Pensar y sentir desde mi historia significa dirigir mis sentidos, mi pensamiento y mi alma hacia lo que me-convive, hacia lo que me- acontece y nos - acontece para sintonizarme con la vida vivida, con mi calle, con lo que pasa y nos pasa; desde los lugares de encuentros y desencuentros donde nos descubrimos con los otros, reconociéndonos en nuestras miradas, testimonios, experiencias, hechos y acciones en las que participamos desde nuestras singularidades y diversidades. Esta diversidad nos refiere, a procesos de interacción donde se conjugan nuestros acervos, propicios para ambientes comunicativos de apertura y ruptura.

En este horizonte de posibilidades, se ubica la formación docente, como tarea eminentemente humana, donde se busca la realización del ser docente, en tanto ser dialógico; con ética hacia la creatividad y hacia la expresión consciente de aquellos atributos que le confieren su condición humana; para expresar ternura, compasión, perdón y armonía consigo mismo, con la naturaleza y con el prójimo. Esto es posible, mediante prácticas de subjetivación que permiten el cultivo espiritual permanente del ser humano, en una gran religazón con el pensamiento y su razón. Para alcanzar tal aspiración, me propuse provocar espacios desde lugares que "están abiertos a la posibilidad de transformarse en función de un cambio en el campo problemático..." Zemelman, (1992, p. 112), brindando posibilidades desde la polisemia de la realidad.

Las prácticas que se desarrollaron en el transcurso de esta investigación, incitaron a contravenir las formulas del saber instituido, para reinventar nuevas, que se fundamentaron en el diálogo de saberes y en nuevas claves de interpretación conciliables con lo imaginario y lo sensible. Esto me proporcionó oportunidades para re-semantizar el comportamiento del ser desde su condición humana, en escenarios donde cada uno se constituye en su autenticidad. Cobra, así, importancia la situacionalidad histórica de los sujetos que van construyendo su propia historia para hacerse cargo de sus propios proyectos.
2. POSICIONAMIENTO HERMENÉUTICO: UN ESPACIO DE INTERPRETACIÓN COMPRENSIVA

El legado recibido en los ámbitos académicos, referente al modo de investigar, nos acerca hacia una relación causa-efecto de hechos verificables empíricamente mediante entidades concretas, tangibles, mensurables y comprobables. En tal sentido, promover un estudio que involucre las potencias intrínsecas en el ser humano requiere de formas y modos que rebasan estos procedimientos, pues requieren una visión e interpretación de índole distinta

En sintonía con lo anteriormente dicho, en esta investigación, asumo un posicionamiento hermenéutico, por ser este el camino que reúne estilos y elementos de análisis apropiados para involucrar la espiritualidad del ser humano y su revalorización subjetiva en la dimensión del fenómeno social. Además, permite interpretar sucesos complejos desde su propia realidad, en situación. Dicho, en otros términos, cuando el investigador asume una investigación desde un posicionamiento hermenéutico, "deslabona" las cadenas del diseño que lo constriñe y lo induce a buscar leyes para generalizar los hechos, y se libera hacia una realidad compleja, donde tiene la oportunidad de realizar estudios de gran profundidad, pero en pequeña escala sin pretensiones representativas; privilegiando el papel de la subjetividad, la intrasubjetividad, la intersubjetividad y la contextualidad.

Desde esta perspectiva, no concibo a la hermenéutica como un método para conseguir la "verdad" acerca de un hecho o fenómeno. Me atreví a trabajar con la hermenéutica luchando contra la idea de una representación exacta del mundo, heredada desde los ambientes de investigación de las ciencias naturales desde donde he obtenido mi título profesional. En tal sentido, apuesto por la promoción del diálogo, en tanto, fenómeno humano revelado en la palabra; en el encuentro de los hombres que en comunión pronuncian el mundo, entre la acción y la reflexión, en un acto creador (Ver Freire, 1987, pp. 99-106), imprescindible para la edificación del ser huma- 
no; y en la argumentación creativa de las relaciones humanas, que hacen posible el encuentro con el otro y su consecuente reconocimiento. Más aún, si de Formación Docente se trata; pues como lo plantea Rorty (1996, p. 65), la forma como se explican los hechos es más importante que la tenencia de la verdad.

En esta línea de pensamiento resulta muy sugerente la afirmación que hace Flórez (1996, p. 217), cuando esgrime que, la hermenéutica le da sentido y significado a las interacciones en las cuales estamos comprometidos con otros, alcanzando una mayor comprensión de las construcciones existentes, lo que lo hace sencillo y comunicable para otros.

Desde esta perspectiva, comparto la concepción de la hermenéutica planteada por el filósofo Heidegger (1983), por lo que dilucido, que la interpretación no es un instrumento para obtener conocimientos; porque, por el hecho del ser, nacer en un mundo de significaciones, implica que no le queda otro remedio que vivir interpretando: la interpretación es una condición histórico-destinal del Dasein humano. Desde esta disposición, la hermenéutica, constituye un modo de ser de los seres humanos, que no puede ser interpretada como un método, en tanto, proceso o camino sistemático establecido, impuesto y predeterminado. La hermenéutica no resulta ser una forma particular de conocimiento sino la que hace posible cualquier forma de conocimiento.

Con esto estoy indicando, que los conocimientos que emerjan antes, durante y después de esta investigación, serán expresiones de dicha interpretación y, estarán ajustados por el movimiento anticipatorio de mi propia precomprensión o de mi propio horizonte de sentido que como investigadora me acompaña como trasfondo prerreflexivo en toda interpretación, como bien lo explican Husserl (1994), Heidegger (1985) y Gadamer (1991). Indiscutiblemente que la dinámica que se desarrolla en esta investigación, requiere de la licuación en un proceso unitario, esencial e integral de los actos de interpretación y comprensión.

\section{APROXIMACIÓN A LA INTERPRETACIÓN DE LA HERMENÉUTICA}

Para entender el significado del término hermenéutica, he recurrido a sus orígenes. El vocablo Hermeneuein o hermeneutikos que significa "expresar", "explicar", "interpretar" y "traducir", tiene su origen en las actividades realizadas por Hermes (Dios de la ciencia, el comercio y la elocuencia), el llamado mensajero de los dioses, el cual era el encargado de comunicar y hacer comprender a los hombres el pensamiento de los demás dioses. Para alcanzar esta misión, Hermes, necesariamente, tenía que interpretar sus enunciados a fin de ofrecer una comprensión de ellos.

En la expresión del pensamiento actual, no concibo esta actividad de Hermes como la de simple mensajero de los preceptos divinos, por lo que le atribuyo una acción más compleja donde se involucran hechos mentales (símbolos, conceptos, concepciones), los cuales a su vez pueden referirse a otros símbolos y estos a otros sucesivamente en un círculo intersubjetivo de significados y valores que van construyendo sus intérpretes de una manera dinámica y espontánea. El trabajo del intérprete, actualmente, no es tan solo reproducir lo que dice la realidad, sino que tiene que hacer, además, la causa suya, y hacer valer su opinión como conocedor de lo que allí acontece.

Es decir, ocurre la expresión de un acto mental como tal. Lo que Husserl (1994, p. 10) llamó acto intencional (noesis) o acto psíquico individual de pensar, el cual se nutre de significado o valor porque se refiere o comprende los fenómenos. De ahí, que Wilber (1987, p. 31), defina a la hermenéutica como la rama de la fenomenología que se ocupa de interpretar los significados de los símbolos intersubjetivos o intencionales.

Platón (260 d), cuando la designa hermeneutiké la concibe como la técnica que hace posible la interpretación de los oráculos o los signos divinos ocultos. La hermenéutica pierde este sentido con Aristóteles para quien hermeneias (interpretación) trata de las proposiciones enunciativas y de los principios de la expresión discursiva. Como ars interpretandi la hermenéutica reviste tres formas con sus propias temáticas regionales, 
en el Renacimiento: (1) La hermenéutica filológica, la cual desempeñó un papel central en la recensión de las obras de la literatura grecolatina, entre ellas las de Homero, (2) La hermenéutica jurídica orientada a la interpretación del derecho y a sentar jurisprudencia, y (3) La hermenéutica jurídica, asumida como exégesis y apologética, adoptada para posibilitar la interpretación de las Sagradas Escrituras.

A Schleiermacher, se le considera el padre de la hermenéutica moderna y con este adquiere un sentido filosófico. Este filósofo se atrevió a estructurar un proyecto de hermenéutica universal que tuviera la autonomía de un método. Presentó una teoría hermenéutica considerando dos dimensiones. La primera dimensión es coherente con el proceso de interpretación de los textos basándose en el contexto social y lingüístico común del autor y del intérprete, pues consideraba que esto hacia posible la comprensión porque ambos poseían una gramática y lingüística común y además, el contexto social común beneficiaba a la empatía durante el proceso de comprensión. En la segunda dimensión añadió a la teoría tradicional de la interpretación una dimensión psicológica donde la persona que interpreta articula un discurso tomando en consideración la actividad discursiva individual de la persona que habla y del contexto social de la lengua. Así, el discurso tendrá un carácter común con la cultura en la que se articula y con el carácter del escritor. Por lo tanto, cada intérprete debe confrontar la dimensión social e individual del texto, pues solo se puede comprender a partir de ese mundo.

Para Schleiermacher, la tarea de la hermenéutica era "entender el discurso tan bien como el autor, y después mejor que él”, esta concepción de la hermenéutica pudiera provocar la ruptura del acto interpretativo. Algunos filósofos contemporáneos como Habermas y Apel comparten esta tesis de Schliermacher. Estos teóricos no han considerado que las aporías del texto, del autor y del intérprete impidan conocer al autor y a su tiempo tan bien como él se conoció a sí mismo y a su tiempo.

Con Gadamer (1991, p. 44), necesito aclarar que, en esta experiencia interpretativa no hay dicotomía entre la teoría y la práctica, ni tampoco entre sujeto y objeto: en el acto interpretativo convergen dos seres en el mundo. Por lo que, en los procesos de formación docente, en tanto, quehacer interpretado de esta investigación, se configura una implicación dialéctica a partir de la cual, los acontecimientos pedagógicos se perciben como praxis educativa-social impregnada de sentidos, significados e intencionalidades desde las cuales la teoría emerge.

Para Dilthey (1990), la hermenéutica es la "ciencia de la comprensión", (Verstehen). La comprensión nos permite interpretar las manifestaciones del espíritu humano a través, de signos sensibles relacionados con los aspectos psíquicos: expresiones gestuales, miradas, articulaciones de la palabra hablada, intencionalidades, señas, mímicas, maneras de expresar situaciones agradables y desagradables; para dar sentido y significado a lo que el otro expresa sin necesidad de mediar palabras.

\section{LA HERMENÉUTICA EN LOS PROCESOS DE FORMACIÓN DOCENTE}

Para facilitar la comprensión acerca de la manera de proceder en esta investigación, he separado esta discusión en tres (3) planos que cuidadosamente, he desarrollado de manera simultánea y no excluyente. El primer plano, lo consideré como etapa de con-figuración del sentido de lo real a partir de la hermenéutica desarrollada a partir de fuentes secundarias. Es decir, desplegué una investigación teórica mediante un proceso de selección y lectura de aquella bibliografía que me mostraba una comprensión profunda de las categorías relacionadas con la problemática estudiada. Los conceptos, concepciones, sentidos fueron debatidos teóricamente siguiendo una lógica transversal, reivindicando los elementos propios de la espiritualidad del hombre, al unísono con el ejercicio epistemológico. De este modo, procedí a investigar y a ubicar textos, revistas, tesis, ensayos y páginas digitales ubicadas en los sitios web, en cuyos espacios escriben autores con autoridad intelectual, referidos a las categorías tratadas y 
a las que fueron surgiendo en la medida que se desarrollaba la investigación.

En este compromiso epistémico, asumí una lectura activa, productiva y creativa de la investigación teórica a través de un pensamiento pedagógico crítico, que me permitió destacar nuevas significaciones, creando y recreando una escritura disímil del texto. Este trabajo hermenéutico, dice Derrida (1997, p. 7), se percibe en Nietzsche y en Heidegger, donde la interpretación sigue un ritmo dinámico y creativo de realización poética de nuevas perspectivas. A medida que iba realizando la lectura comprensiva de los textos, tomaba una posición frente a estos, creando una interpretación propia de las cosas; las cuales construí de acuerdo con mi estilo discursivo y a mi subjetividad (lo que vivo, hago, pienso y siento).

El segundo plano de esta investigación, trabajé con la hermenéutica en la cotidianidad de los espacios de formación docente. Para tal fin, tomé en cuenta, uno de los espacios que abonan los procesos de formación en los que intervinieron los docentes en servicio del subsistema de Educación Básica del Sistema Educativo venezolano. Seleccione, atendiendo a algunos criterios (grupo con información relevante acerca de la problemática en estudio, compartían con la investigadora sus procesos de formación, entre otros), a 20 docentes como actores claves. Procedimos a ejecutar, un proyecto de trabajo participando en eventos reales desde distintos contextos de la cotidianidad.

Consideré apropiado deliberar procesos de investigación desde la experiencia, para entender las relaciones que involucraran a los docentes, en su formación desde una visión sensible, integrándolos al contexto histórico donde se realizan en sintonía con sus conceptos, símbolos y expresiones, atendiendo la afirmación de Wilber (1987, p. 34), cuando esgrime, “... Si uno está dentro del círculo hermenéutico, el acuerdo interpretativo consensual es la validación", porque en lugar de imposiciones, será la negociación la regente de tales relaciones. Además, es desde el interior del círculo donde el diálogo alcanza una estructura perfecta en el juego de la pregunta y la respuesta al mejor estilo de la mayéutica socrática.
Debido al carácter hermenéutico de esta investigación, no me propongo la objetividad como objetivo metodológico, sino como examen cruzado de información y en el contraste de diversas intersubjetividades, como resultado de la relación entre seres humanos. En este encuentro intersubjetivo lo lingüístico se encuentra en lo hermenéutico; por lo que, la comprensión de las ideas que se expresan en los instrumentos aplicados se concibió como un evento dialógico; donde el intérprete-investigador no anuló el pensamiento antagónico del otro, sino que, por el contrario, se pretende buscar la potencialidad y el significado de cada reflexión, por lo que la comprensión supone aquí una fusión de horizontica. Esta posición es enganchada a esta propuesta de trabajo ya que, como señala Gadamer (1999),

No podremos nunca tener un conocimiento objetivo del significado de un texto o de cualquier otra expresión de la vida psíquica, ya que siempre estaremos influidos por nuestra condición de seres históricos: con nuestro modo de ver, con nuestras actitudes y conceptos ligados a la lengua, con valores, normas culturales y estilos de pensamiento y de vida (p. 333).

Por lo tanto, cada intérprete examina la dimensión social e individual del texto. Esto hace que la tarea interpretativa sea infinita. Cada traductor puede re-crear la actividad creativa y mental del autor a través del proceso interpretativo; en el cual el ser, a decir del autor anteriormente citado, se identifica con el lenguaje, cuando señala que "el ser que puede llegar a ser comprendido es el lenguaje". El lenguaje es, en definitiva, lo propiamente humano, por lo que cada acción humana lleva consigo un componente interpretativo que emerge desde el lenguaje.

Esto está indicando, entonces, que las verdades no son absolutas, sino que son frágiles, revisables, sujetas a controversia y a fin de cuentas perecederas. Por lo que es comprensible que cada persona posea su propio horizonte de interpretación, el cual construye y reconstruye constantemente para comprender-se y comprender su contexto mediante la argumentación y el debate de ideas. En este sentido, esta perspectiva lingüístico-dialógica se contrapone a un cierto

\section{Cumbres}


relativismo interpretativo (lingüístico, cultural, social, e histórico) que ronda por los escenarios educativos en la actualidad.

\section{MOMENTO ESTRUCTURAL ONTOLÓGICO DE LA COMPRENSIÓN}

El significado de las dimensiones simbólicas que se expresan en la realidad de la problemática aquí estudiada, tienen gran importancia; más aún por su carácter abierto, dinámico y en constante construcción desde la contextualización de problemáticas vividas y sentidas en nuestras convivencias como seres humanos; por lo que el enfoque comprensivo y sus técnicas conexas constituyen la mejor vía para buscar los significados en el ámbito de la praxis educativa y sus relaciones.

Refiriéndose a la intromisión del investigador educativo, como participante de los procesos de comprensión; Varela-Villegas (2002, pp. 121122), señala que este, al penetrar al terreno de estudio, necesita apoderarse del lenguaje de sus miembros para tener acceso a la información requerida y así, poder entender las relaciones ocultas de sentido, por lo que la comprensión de lo educativo es una expresión de una práctica comunicativa, donde el método de la comprensión supone la participación del investigador educativo en la acción comunicativa.

Las interpretaciones las realicé a partir de las experiencias vividas con cada grupo; en las cuales desarrollaban interacciones intersubjetivas y contaban una historia con un sello personal, haciéndome olvidar de mí misma, para contemplarme desde la perspectiva de ellos. Pues de lo contrario, se hubiera desarrollado en mí el vaciamiento de los asuntos meramente académicos alejándome del significado y la riqueza que cada experiencia posee. Es decir, el plexo de significados intersubjetivos que compartimos estuvo, en todo momento, enriquecido por la interacción con los demás en una fusión de horizontes potenciando mi carácter social y humano.

Es necesario destacar, también, que en los procesos en los cuales participé, no siempre los docentes se mostraban transparentes; esto es, mostraban su personalidad y espíritu de trabajo; bien sea por la carencia de relaciones empáticas entre miembros de grupos diferentes o entre los miembros del mismo grupo y, porque no decirlo, entre algunos participantes y mi persona. Esto ocasionó que emergieran situaciones de confrontación donde se expresaron un entramado de elementos estructurados y/o espontáneos. De ahí que, desde una posición hermenéutica pude, además, interpretar los mecanismos que ocultan realidades falseadas del evento vivido. En este sentido, tiene razón Heidegger (1983, p. 129), en su libro titulado ser y tiempo, cuando señala, que la hermenéutica particular de estas relaciones empáticas, tendrá que mostrar que las diversas posibilidades de exteriorizarse el ser pueden llegar a falsear y deformar la convivencia y el conocimiento que de ella emerge, impidiendo la emergencia de una comprensión auténtica, haciendo que el Dasein se refugie en sucedáneos.

Asimismo, el citado filósofo apunta que "El hombre, en cuanto abierto al ser, es el intérprete privilegiado del ser" por lo que, me convertí en la intérprete comprensiva de mi propio problema de investigación. Esta clara práctica de alteridad me permitió apreciar desde una visión intra-subjetiva el significado que tiene ese lugar de encuentro para la Formación docente; haciendo posible la aparición del círculo hermenéutico, en el cual se considera que toda interpretación que haya de acarrear comprensión tiene que haber comprendido ya lo que se trate de interpretar.

Esta estructura de anticipación privilegia la pre-comprensión necesaria en todo acto en el que se pretenda comprender lo interpretado. Vattimo (1996, p. 126), por su parte lo hace más comprensible cuando señala, "no es algo que se construye o se desarrolla con un simple ejercicio del pensamiento, sino que depende de un cambio del ser mismo como apertura histórica del ser en el mundo en el que el hombre está lanzado", para pensar originariamente, ya no como la comprensión de un texto en su contexto, sino que así se desencadena una comprensión que integra a su vez la auto-comprensión del investigador que aparece por medio del lenguaje, y por ende, se hace recursiva en él. 
En este sentido, la hermenéutica es condición de posibilidad de todo conocer; por lo que, la comprensión y la explicación son imposibles sin la interpretación en la totalidad donde el investigador es el intérprete, por lo que éste se expresa en un modo de ser que supera la simple aprehensión de los procesos cognoscitivos, donde tendrá que interrogar permanentemente la realidad, confrontando los conocimientos o ideas con el mundo.

\section{DESCRIPCIÓN FENOMENOLÓGICA DE LA INVESTIGACIÓN}

Para alcanzar los objetivos trazados en este trabajo hermenéutico, fue necesario seleccionar una unidad social de investigación, la cual estuvo conformada por treinta y seis (36) integrantes (docentes en servicio del Subsistema de Educación Básica venezolano), y por 10 docentes universitarios que acompañan mediando el proceso de formación de estos docentes. Los docentes en servicio, formaron cuatro (4), grupos de trabajo los cuales se comprometieron a elegir distintas problemáticas ubicadas en el contexto de la realidad social que los acontece.

Los docentes en servicio del subsistema de Educación Básica formaron grupos de trabajo. Cada uno seleccionó un espacio simbólico real, para interpretar desde ahí la expresión de una problemática; insertando su "pensamiento-lenguaje referido a la realidad, los niveles de percepción sobre esta realidad, y en su visión del mundo" (Freire, 1987, p. 113). Es decir, los contenidos académicos no fueron tratados a la manera tradicional, sino que fueron aprehendidos en su complejidad, en su riqueza, en sus significados, en su acaecer, en su constitución histórica desde el espacio en el cual se encuentran envueltos.

A medida que los docentes en servicio asumieron esta responsabilidad y compromiso y se iban insertando en la realidad con su problema en estudio, surgiendo en ellos nuevas maneras de ver las vicisitudes que, otros enfrentan, en este caso, los actores sociales y, en consecuencia, comenzaron a expresar un sentir distinto acerca de ese mundo de vida. Cada estudiante (docente en servicio o docente de Educación Básica), a medida que iba viviendo su historia dentro de la comunidad, registraba sus inquietudes en los diarios del participante. Estos diarios los orienté, mediante la formulación de interrogantes. Según Lankshear y Knobel (2003, p. 18), los diarios del participante son artículos donde se pide a los participantes que asienten por escrito sus opiniones personales y sus reflexiones acerca de un acontecimiento o una práctica relacionada con su quehacer. Además, iban recogiendo cada experiencia vivida en un video, para su posterior discusión, en una plenaria grupal.

En estos espacios, cada grupo exponía sus experiencias vividas. Destacaban, en las discusiones, no sólo el peso cognoscitivo que tuvieron los tópicos trabajados, sino, también cómo les había impactado como personas, como seres humanos en relación con otros. Evidenciaron, además, la toma de conciencia en torno a ellos mismos, y a la realidad expresada a través de su pensamiento-lenguaje referido a un mundo significativo y simbólico. De este modo, compartíamos momentos de construcción-creativa, de argumentación, de compromiso ético, de conocimiento, reflexiones, sensibilidades y pensamientos. Donde, además, se reconstruían espacios adecuados para formar-nos, relacionar-nos, convivir-nos, comprender-nos y sentir-nos. Emergiendo la comprensión común de los desafíos, acontecimientos y hechos estudiados.

El primer grupo dispuso investigar la situación de los niños de la calle, conocidos en la cotidianidad como "huele pega". El segundo se inclinó por los modos de vida, cultura y perspectivas de los vendedores de pescado de la zona. El tercer grupo, decidió investigar la situación de los niños autistas y el cuarto grupo, las condiciones de vida de los ancianos ubicados en el Asilo de Ancianos de la región. Cada investigación, permitió develar un infinito cultural involucrando mitos, sueños, ciencia, ética, historia; implicando la complejidad infinita de la vida subjetiva de personajes inéditos y anónimos enfrentados al destino social.

En cada investigación, la propuesta planteaba espacios de convivencia o interrelación con las 
personas involucradas, entrevistas a personajes claves; y por su puesto, la necesaria interrelación de los participantes de cada grupo de trabajo. Al principio la integración de los equipos y puesta en marcha del proyecto no fue fácil. Los coordinadores de cada grupo alegaban irresponsabilidad por parte de algunos miembros, falta de tiempo; el cual debían compartir entre su trabajo como docentes en servicio, sus estudios en la universidad y sus responsabilidades familiares.

Otros se quejaban por la exigencia de la investigación pues reclamaban sus espacios académicos que ellos denominaban "normales"; basados en exámenes, exposiciones y trabajo, como consecuencia, de las secuelas dejadas por el positivismo. Mientras que otros acudían a la desidia y a la evasión de la responsabilidad, dejándola en manos del compañero amigo, seguros de que al final serían incluidos como activos trabajadores. Pero, al darse cuenta que su poca actividad se vería reflejada en el video, decidieron abandonar.

Así, finalmente, de treinta y seis participantes sólo quedaron veinte (20), con los cuales se realizaron las tres propuestas finales: diez (10), de los docentes en servicio, se responsabilizaron en sacar adelante la propuesta de estudio de la situación de vida de los vendedores de pescado; cinco (5) docentes, asumieron la proposición de los niños autistas y, cinco (5), docentes en servicio, trabajaron con la investigación de los estilos de vida de los abuelitos en el Asilo de Ancianos.

Estos docentes, se dirigieron hacia contextos seleccionados por ellos mismos. Para tal fin, enviaron solicitudes de acceso y se insertaron, mediante visitas realizadas tres veces a la semana durante seis meses, en sus espacios de investigación donde se ubicaba su problemática. En estos lugares entablaron relaciones afectivas y se interrelacionaron con los participantes de la realidad estudiada. La experiencia fue recogida en un video, el cual fue presentado en la discusión final.

En cada investigación, la propuesta planteaba espacios de convivencia o interrelación con las personas involucradas, entrevistas a personajes claves, y por supuesto, la necesaria interrelación de los participantes de cada grupo de trabajo. En el caso de la realidad de los pescadores; los docentes entrevistaron en pleno escenario donde ocurrían los acontecimientos a tres pescadores, dos trabajadores que arreglan el pescado para la venta, a cuatro vendedores, a dos compradores de pescado y a un representante de los organismos de seguridad del área.

En el caso de las visitas al Centro de Atención Integral de las personas con Autismo (CAIPA), sólo permitieron realizar las entrevistas; la convivencia con los niños fue negada, aludiendo que no se podía violar la privacidad de los niños. Sin embargo, los investigadores convivieron y compartieron experiencias con la directora del centro y dos especialistas del área.

Una vez concluida esta etapa de la investigación, nos congregamos en una plenaria. Acordamos dedicar veinte (20) minutos para que cada grupo presentara su video y la interpretación respectiva de los hechos. Una vez concluida la presentación de los tres videos de manera simultánea, dimos paso al diálogo intersubjetivo. Cada docente en formación, tomaba la palabra acerca de la presentación realizada por su grupo y por los otros grupos; interpretaban su propia presentación, la de su grupo y la de los actores comunitarios que van apareciendo en el video. Posteriormente, escribían en el diario de participantes las preguntas relacionadas con su investigación.

La idea fundamental de esta actividad fue crear un clima de diálogo, encuentro y contraste donde cada docente participara libremente sin evasiones ni manipulaciones. Pude apreciar durante las discusiones que, en estos tejidos, los docentes ensamblan su pensamiento con su sentir, construyendo un mundo de posibilidades a través de su lenguaje. Aprenden a vencer sus propios miedos enfrentándose a los desafíos de la realidad. Se animan a establecer diálogos más humanos con personas diferentes desde el punto de vista social, físico y económico. Comienzan a sentir compromiso y responsabilidades consigo mismo y, con el otro u otros con los que interactúan sin presiones ni tensiones. En otros términos, el docente experimenta nuevas sensibilidades, otra forma de pensamiento y otro tipo de relaciones con el otro, donde lo reconoce como legítimo otro. 
Para alcanzar un mayor cruce intersubjetivo de conciencia entre los actores involucrados, apliqué una entrevista abierta, a diez (10), docentes universitarios (coagentes claves), facilitadores en el Programa de formación de los docentes en servicio. Esta entrevista constituyó un espacio para el desarrollo de conversaciones afectivas y amenas, en ambientes de relación, constituidos en el "lenguajear" como diría Maturana (2008, p. 23), refiriéndose al carácter dinámico relacional del lenguaje; siguiendo un discurso intersubjetivo, en tanto, lugar auténtico de argumentación. Establecí relaciones de respeto, consideración y admiración por el modo como estos seres humanos enfrentan el mundo y su quehacer educativo haciéndolo habitable.

Siguiendo esta dinámica, la entrevista abierta, no estuvo constituida por preguntas estandarizadas ni directivas. No obstante, tengo que aclarar que, elaboré un guión para que me sirviera de guía con las principales categorías. Las categorías desarrolladas, fueron en todo momento pertinentes al mundo de la vida universitaria en la que éste desarrolla su quehacer docente; cada docente narraba secuencias de acciones relacionadas con sus experiencias pedagógicas, con lo vivido y sentido. Además, en el desarrollo de la conversación tuvieron cabida afirmaciones ambiguas del entrevistado, reflejando las contradicciones del mundo que habita; por lo que emergieron nuevas intuiciones y tomas de consciencia que, en algunos casos, lo hicieron cambiar los significados que ya tenían construidos.

Asimismo, los imaginarios recogidos durante la entrevista, fueron expresados siguiendo el estilo discursivo de los entrevistados y no por la cuantificación del mismo; Por mi parte mantuve una actitud de apertura a los fenómenos nuevos e inesperados que iban surgiendo durante la experiencia, por lo que me desprendí de las categorías estandarizadas y esquemas de interpretación.

De este modo, recopile un conjunto de testimonios y referencias que me permitieron, posteriormente, identificar tendencias o preferencias de estos docentes en sus prácticas educativas. Pude, a su vez, captar expresiones no verbales que me ayudaron posteriormente en la interpre- tación y comprensión de las opiniones y reflexiones efectuadas por los docentes en formación. El resultado de este trabajo fue recogido en una grabación de voz en un mp3, para posteriormente transcribirlas mediante repeticiones detalladas y minuciosas.

Durante y después del desarrollo de este plano de la investigación, realicé la descripción e interpretación de los acontecimientos ocurridos en los distintos videos, en el diario de participantes, las reflexiones e intercambios en el aula con los estudiantes y las entrevistas realizadas a los docentes universitarios. El contraste de estas fuentes me permitió avanzar cualitativamente para tener mayores argumentos al momento de realizar la interpretación-comprensiva de esta compleja realidad interactiva: proceso de formación docente.

\section{PROCESAMIENTO DE LA INFORMACIÓN OBTENIDA DURANTE LA INVESTIGACIÓN, DESDE EL CRUCE INTERSUBJETIVO DE CONS- CIENCIAS}

El cruce intersubjetivo de Consciencias se entiende, en este estudio; como la intersección dialéctica que ocurre en el diálogo de saberes, entre los saberes de los actores sociales (docentes Universitarios, Docentes en servicio del subsistema de Educación Básica) recogidas en los diferentes instrumentos y las reflexiones, supuestos, consideraciones y concepciones del investigador. En tal sentido, en estas actividades intervine con mecanismos de integración y de construcción utilizando tanto mis conocimientos lingüísticos como mi saber pedagógico. Para la interpretación de significados durante la comprensión utilicé dos tipos de procesos: la integración y la interpretación constructiva de sentido.

La integración consiste en conjugar en una representación única los distintos tipos de información. A los procesos interpretación constructiva de sentido o también llamados procesos inferenciales. Gutiérrez (1999, p. 231) los define como "representaciones mentales que el lector/ oyente construye o añade al comprender el texto/ 
discurso, a partir de la aplicación de sus propios conocimientos a las indicaciones explícitas en el mensaje". Por lo tanto, implican la incorporación de información nueva que no estaba explícitamente mencionada en el mensaje original. Fue por este camino, como me pude insertar en un proceso constructivo de sentido a partir de las informaciones suministradas en los dos instrumentos (diarios de participantes y las entrevistas), aplicados a los docentes pertenecientes al subsistema de Educación Básica y a los docentes universitarios. Para alcanzar estos propósitos procedí de la siguiente manera:

\subsection{La faena continúa}

Una vez sistematizada la información recopilada. Realice lo siguiente:

- Transcribí la información, tanto de las entrevistas realizadas a los Docentes universitarios, como las presentadas por los docentes en servicio, del subsistema de Educación Básica, en su diario de participante.

- Realicé una selección minuciosa de la información considerando dos criterios fundamentales: pertinencia y relevancia, (Cisterna, 2005, p. 68). En el primero, tome en cuenta aquellas cuestiones contenidas en las respuestas dadas, que se relacionaran con las categorías macros de la investigación. En la segunda, las que fueron develándose en el desarrollo de la investigación.

- Corté en bloques, literalmente, las respuestas emitidas y las agrupé por temas de acuerdo a las preguntas que orientan esta investigación, generando una unidad temática o macro-categoría determinada.

- Busqué el sentido de la información suministrada por cada actor (docentes en servicio del subsistema de Educación Básica y Docentes Universitarios) lo que me "sugirió" los temas, unidades temáticas o macro-categorías.

- Para realizar la interpretación de la información acopiada, fue necesario, combinar este proceso, con el uso de la descripción permanente de las situaciones, acciones, productos, actitudes y comentarios surgidos de los sujetos involucrados.

- Del mismo modo, efectué intersecciones intersubjetivas entre las teorías investigadas y la información recogida.

\subsection{Cruce intersubjetivo de consciencia entre} las informaciones suministradas en cada uno de los instrumentos aplicados y el investigador.

Esta intersección se realiza con el contenido intersubjetivo que cada uno de los actores (docentes en servicio y docentes universitarios) expresan. Por eso, se aplica en cada instrumento utilizado. Para realizar esta intersección, tomé en cuenta los saberes expresados por los diferentes actores involucrados en esta investigación, para ello agrupé las respuestas según su coincidencia o su divergencia. Tanto las del diario del participante; como las de las entrevistas realizadas a los docentes universitarios. Estos instrumentos me permitieron conocer los supuestos que en relación a la problemática de la investigación tiene cada uno de los actores involucrados, en relación a las preguntas centrales de esta investigación. Este empalme intersubjetivo, me permitió establecer relaciones de comparación entre las respuestas que actores diferentes dan acerca de una categoría determinada, en función de los diversos tópicos interrogados. Es decir, entre las respuestas dadas por los docentes universitarios y docentes en servicio del subsistema de Educación Básica. Este ejercicio, enriquece el contexto intersubjetivo, desde donde se construyen significados.

\subsection{Cruce intersubjetivo de consciencias entre cada grupo de actores y el investigador.}

En este diálogo de saberes se franquean en la discusión, por separado docente universitario-investigadora y docente en servicio del subsistema de Educación Básica con el Investigador.

\subsection{Cruce intersubjetivo de consciencias entre las fuentes de información y el marco teórico utilizado en esta investigación.}

El marco teórico constituye la fuente esencial 
para la desarrollar el proceso de construcción de conocimiento en toda investigación. En tal sentido, ahora, se retoma en la investigación para producir una nueva discusión con los resultados de la investigación.

\section{NUEVAS CONFIGURACIONES AL ENFREN- TAR LOS DESAFÍOS DE LA FORMACIÓN DO- CENTE}

El recelo hacia investigaciones enclaustradas en un recinto no significa, de ningún modo, la imposibilidad de abrir ventanas hacia una vida efervescente y seductora. Muy al contrario, esto puede incitar hacia una estética intelectual, que despierte el furor de vivir para experimentar con el otro, emociones que nos hagan recordar, que el ser es acontecimiento, pasión, controversias, que se viven en la intensidad de la realidad como horizonte histórico de sentidos posibles; "en el vitalismo de lo que ocurre, del acontecimiento, del transcurrir efímero que es el lazo social...", como dijo Maffesoli en una entrevista realizada por Sanabria (1997). Entender esto significa, Poner énfasis, en las exigencias de la realidad, en el coraje de vivir, en el furor de sus controversias políticas, en las manifestaciones sociales de jóvenes que se oponen a los diversos imperativos categóricos formulados por el moralismo moderno bien de orden sexual, económico, ideológico, social; entre otros; para resemantizar un modo otro, de entenderla, proponerla y construirla con el afán de encontrar desconocidos horizontes históricos en relación a una nueva ética, estética y sensibilidad.

Obviar esta realidad, desde los espacios de Formación Docente, que forma para la vida, ya no es posible. De ahí, quizás, los encuentros, en esta discusión, entre lo que expresan los docentes universitarios y los docentes en servicio del subsistema de Educación Básica. Desde diferentes ópticas, la mayoría de los docentes, coinciden en la necesidad de establecer una estrecha relación entre realidad y formación como espacio para despertar sensibilidades. Desde esta perspectiva, la posibilidad de salida para una formación docente, lo constituye la investigación permanente, en la diversidad metodológica; para que los docentes puedan aplicar “...estrategias que lo comprometan y animen a ser agente motivador por una sociedad más humana...", como uno de ellos apuntó. Además, coinciden en testificar que son los espacios para desarrollar sensibilidades propias y conocer las sensibilidades de otros congéneres mediante la inserción, la participación y resolución de los problemas del otro.

Otro pilar clave, estrechamente vinculado con el conocimiento, está ligado a las siguientes opiniones: “...como no vivimos ese tipo de realidades no hay la debida sensibilidad para el resto del mundo...” "...la realidad de los problemas está más allá de lo que imaginamos...". Si consideramos que el conocimiento es selectivo, podemos desprender, que esa capacidad de selección y procesamiento de información, se relaciona con una específica manera de entender la realidad social y de actuar sobre ella.

De tal manera que, el modo como imaginamos, pensamos y concebimos la realidad, determina la forma como asumimos la vida en el campo personal y social. Nos organizamos, actuamos y estructuramos nuestros conocimientos según este enfoque. Si tenemos una visión limitada y simple de esa realidad, será imposible avistar y pensar la complejidad de lo real. También la complejidad de nuestra época y la complejidad del problema del conocimiento.

De ahí, la necesidad de atender, las realidades cada vez más complejas, globales, impredecibles y urgentes, que no son consideradas por los campos disciplinarios de las universidades. Esto se constituye en una posibilidad emancipadora, que rescata el papel de la formación, en tanto, inclusión de la sensibilidad y reconocimiento del otro; recuperación de la enseñanza como vía de pensar el conocimiento y la generación del diálogo de saberes permanente, mediante una dialógica intersubjetiva capaz de romper el celofán de las disciplinas, abriendo posibilidades hacia los enfoques y visiones transdisciplinarios, oportunos para provocar la formación de un ser humano desde nuevas configuraciones. Se trata, de abrir posibilidades de diálogo de saberes, entre el uni- 
verso simbólico y las casuísticas que trae el estudiante y el que el currículo le señala; fundadas en una ontología de lo humano que se construye lidiando con la vida. A continuación, un ejemplo de lo planteado, expresado en los diarios de participantes de los docentes en servicio del subsistema de Educación Básica venezolana.

Docente $\mathrm{N}^{\circ} 1$ : Docente en Servicio de $4^{\circ}$ Grado ¿Dónde y por qué seleccionó este problema? Describa el problema seleccionado.

La realidad de la comunidad de pescadores de la Boca de Río. El problema está reflejado desde el punto de vista de la forma de vida de los pescadores, vendedores y otras personas que ejercen esta profesión. Lo que me llamó la atención de esta problemática es que, a pesar de ser una actividad productiva, es calificada cómo una actividad Para la gente pobre, sin valores y un trabajo sucio. Pero lo que se quiere demostrar es todo lo contrario, que ellos son personas que sienten, tienen sueños y una profesión; que a pesar de ver su familia realizada no se avergüenzan de tener este trabajo. Aquí hicimos entrevistas a los pescadores, a los vendedores de pescado, a los que trabajan limpiando el pescado para conocer de viva voz lo que sienten, lo que sueñan, lo que hacen, lo que piensan.

Docente $\mathrm{N}^{\circ} 2$ : Docente en Servicio de $2^{\circ}$ Grado

El problema fue seleccionado en consenso por el grupo en el aula de clases. Es decir, fue sometido a consideración y todos estuvimos de acuerdo con el problema seleccionado. Porque consideramos desde nuestra óptica que es una comunidad que está olvidada y que por sus condiciones de vida pensamos que carecen de valores, pero resultó ser lo contrario. Son seres que conservan sus propios valores, que sueñan.

Docente $\mathrm{N}^{\circ}$ 6: Docente en Servicio de $6^{\circ}$ Grado Seleccionamos la vida de los vendedores de pescado ubicados en el Dique, en la ciudad de $\mathrm{Cu}$ maná y de algunos pescadores. Nos pareció un tema importante. El problema trata de las vivencias que tienen estas personas y conocimos cosas que no pensábamos que existían acerca del tra- bajo que realiza esta gente.

Docente $\mathrm{N}^{\circ} 10$ : Docente en Servicio de $3^{\circ}$ Grado

La problemática de los pescadores que están en la boca del río manzanares en el sector el Dique, en la ciudad de Cumaná. Porque queríamos valorar el esfuerzo humano que día a día hacen estos pescadores para sostener a sus familias. Queríamos conocer sus vivencias y la realidad de ese grupo de pescadores artesanales.

Docente $N^{\circ} 5$ : Docente en Servicio de $6^{\circ}$ Grado

Seleccionamos la forma de vida de los ancianitos en el asilo de ancianos ¿Por qué? Bueno porque primero este es un lugar muy poco comentado; segundo porque esta institución sólo la utilizamos como punto de referencia y no nos atrevemos a conocerla, no mostramos interés alguno por este espacio o por lo que ahí pasa, en pocas palabras, no nos importa. Quisimos aprovechar la oportunidad para saber acerca de la realidad que ahí se vive.

Docente $N^{\circ}$ 6: Docente en Servicio de $1^{\circ}$ Grado

Seleccionamos el asilo de ancianos porque me conmueven una gran cantidad de ancianitos que en lugar de estar con sus familiares están ahí o bien porque sus familiares se fueron muriendo y no tiene quien los cuide o porque sus familiares los llevan ahí para salir de ellos. Pero a pesar de sus problemas ellos son optimistas y dicen que están acostumbrados a ese ámbito y no les hacen falta las visitas familiares porque con el trato que les dan las hermanas los hacen sentir bien.

Docente $\mathrm{N}^{\circ}$ 9: Docente en Servicio de $3^{\circ}$ Grado

El problema seleccionado está relacionado con el proceso educativo de los niños con discapacidad, en este caso, con el síndrome "autismo". Enfocamos nuestro objetivo en recabar la información para mostrársela a los compañeros del curso. Esto lo consideramos importante ya que en la actualidad estos casos tienen que ser admitidos en aulas de clases, por lo que nos pareció importante que sepan dónde deben dirigirse, que sepan que en Cumaná la institución encargada de orientar a los docentes en esta materia 
es el Centro de Atención Integral de las personas con Autismo (CAIPA). Esto con el fin de ayudar al niño, en primer lugar $\mathrm{y}$, al representante, haciéndole entender que esto es una dificultad que podemos superar.

Docente $\mathrm{N}^{\circ} 12$ : Docente en Servicio de $5^{\circ}$ Grado

En el Centro de Atención Integral de las personas con Autismo (CAIPA). Porque el autismo es una situación que personalmente me atañe, porque trabajo con niños autistas y me gustaría aprender mucho más y, además, quise compartir esta experiencia como una reflexión. Porque el autismo es una condición que se puede presentar bien en la familia o en el salón de clases y no nos damos cuenta por no tener el conocimiento necesario.

Son muchos los aspectos que en clave sensible se pueden destacar en esta experiencia. Interesa, en este momento, acentuar el goce que experimentan, estos docentes en formación, por la oportunidad que se les brinda para manifestar libremente sus aptitudes y fuerzas creadoras. Se tratan de vivencias intencionales, ya que el sujeto cognoscente (docente en servicio), se dirige a la realidad estudiada de manera intencional que es el correlato pleno del acto de conciencia. Cobra importancia así, la noción de intencionalidad (Husserl, 1994, p. 198), como propiedad fundamental de la conciencia.

Se denota de esta manera una percepción dirigida intencionalmente hacia algo, de allí su relación de valor hacia una experiencia deseada; pero, unida a un "vínculo dialógico" y a un "vínculo humano", (Gadamer, 1993, p. 12), porque denota la capacidad del ser humano de abordar lo que necesita y en función de ello orientar sus potencialidades y logros. Es una oportunidad importante para recordar que se es humano, en tanto, se es capaz de formar-se para acoger y escuchar al otro, orientando toda convivencia hacia el desarrollo de sus potencias creativas comunes, lugar de expresión y práctica de la comprensión, la solidaridad y el enunciado de todas las potencias del ser.

Al escuchar las expresiones, es posible darse cuenta como estos docentes, durante su formación docente, adolecen de un mayor contacto con las problemáticas reales de su comunidad; aun cuando existen algunos que muestren indolencia, no son la mayoría. Por esto es importante que se inserten en escenarios de creatividad donde puedan expresar sus sensibilidades y provocar el despertar de sus conciencias anestesiadas.

Cuando a estos docentes en formación se les brinda la confianza necesaria para la ejecución de proyectos reales, afloran en ellos sentimientos y emociones que lo acercan a considerar lo que el otro es, lo que el otro siente, lo que el otro representa en esa comunidad. Aprenden a trabajar en conjunto, a tomar decisiones democráticas, a valorar lo que el otro dice o hace, a no anular los criterios, reflexiones y opiniones del otro. Les permite, además, darse cuenta que existen otras realidades diferentes a la suya, con valores de convivencia igualmente importantes. Además, el docente, comprende la necesidad de involucrarse con problemas complejos que pudieran implicar a sus propios estudiantes lo que demuestra una sensibilidad especial por prepararse para ayudar al otro, para estimar al otro y no para juzgarlo y pre-enjuiciarlo.

Se beneficia como dice Morín (2002, p. 24), "la aptitud natural del pensamiento para plantear y resolver los problemas... de nuestra propia condición y de nuestro tiempo". Son propicios estos escenarios de formación porque permiten la interconexión subjetiva de identidades diferentes, propio para escuchar la voz del otro; para identificarse con sus problemas y vicisitudes en una doble dirección: entre el grupo que dialoga para acordar las estrategias de trabajo y entre el grupo de trabajo con los habitantes de la realidad en estudio. Se trata de reconocer la unidad dentro de lo diverso y viceversa, reconociendo la unidad humana a través de las diversidades individuales al igual que su reciprocidad, como lo explica el citado autor.

Las exigencias de esas realidades provocan que el docente en formación, reflexione acerca de su propia práctica. Son elocuentes, en este sentido, las palabras de la docente Marisol, quien expresó:- "La realidad que esta gente vive en sus 
faenas de pescar; trabajo tan difícil y duro,... se muestran responsables...no existe la pereza, hay deseos de superarse y grandes sueños de surgir"; estas palabras, son recursivas en el quehacer del docente, ya que propicia oportunidades para repensar el gran compromiso ético constituido desde la encarnación de lo sensible, de aquellos aspectos de las relaciones sociales que facilitan en el docente, la acción de responsabilizarse por el otro y hacerse cargo del otro, en una relación donde se valora la diferencia.

Pero, ¿Qué está haciendo el docente universitario para provocar encuentros con esa realidad problematizadora y sensibilizadora? ¿Cómo se siente el docente universitario cuando tiene que enfrentarse a estos desafíos de las exigencias, controversias y contradicciones de la convivencia académica? ¿Asume el docente universitario estos retos en su quehacer educativo? A continuación, cito algunas opiniones de estos docentes al ser consultadas acerca de este tema y confrontaré, algunas opiniones que, acerca del tema en discusión, también plantearon los Docentes Universitarios.

Docente Universitario B. (Entrevista realizada el 4 de julio de 2010)

En esta conversación, estuve con una jovencita de aproximadamente veinticinco años de edad, de contextura gruesa y rostro muy afable. En su lenguaje, deja escapar con mucha simpatía los modos de hablar de la juventud de la época. Iniciamos la conversación, pero en su tono de voz y el movimiento las manos, se denotaba cierto nerviosismo que poco a poco fue desapareciendo, en la medida que yo escuchaba con atención y sin interrumpir su decir. Refiriéndose al tema expone:

Yo suelo hacer mis actividades dentro del aula, siempre he tenido la inquietud de mandarlos a hacer observaciones en los colegios, pero...; los docentes me traen sus experiencias porque ellos están en la escuela... a ellos les molesta un poco cuando le dices tienes que ir a la escuela porque vienen cuadrados que todo tiene que ser aquí, a ellos le molesta, les incomoda; lo he intentado, pero si el grupo dice no, entonces no...
Evidentemente, esta docente, se mueve en un escenario donde la búsqueda del placer, la curiosidad y la seducción son resguardados, en tanto, impide que el estudiante (docente en formación), se comunique con las fuentes eróticas del saber que invitan a la búsqueda del placer del conocimiento; pues se adapta a una visión reduccionista, sin cambios profundos donde corre menos riesgo en el hacer nada.

El estudiante, por su parte, amarrándose al poder de la irreverencia y la terquedad, acude a mecanismos de defensa que van desde la mimesis con el docente hasta convertirse en un rebelde que se somete y es sometido a la pasividad, aislado de una relación dialógica se le impide reconstruir su historia.

Docente Universitario A. (entrevistada el 15 de julio de 2010)

Es una persona muy segura, con un diálogo fluido y una formación profesional muy sólida. Dice ser socióloga, y que por lo tanto está aprendiendo a ser y hacer la docencia en esta etapa como profesora universitaria; por lo que expresa muy segura: Yo me he desarrollado como docente y he aprendido a ser docente a través de mi experiencia en Educación Integral. Conversa con mucha ansiedad, queriendo decir muchas cosas a la vez. Expresa a través de su diálogo, un gran compromiso ético con lo que hace y dice. En la medida que conversa parece disfrutar al recordar las experiencias con sus estudiantes, a los cuales dice agradecerle el desarrollo de su sensibilidad como docente. Sin embargo, responde:

...Para mí el mejor espacio es el salón de clases, el mejor el mejor el mejor de todos, porque me encuentro conmigo misma, con mis estudiantes y hacemos un encuentro donde compartimos...

La educación y las formas de comprenderla cambian según sea la acción de los actores sociales que intervienen en ella. Si partimos del hecho, de que en el proceso educativo intervienen lo sensible, estético y afectivo entre sus actores, entonces, la formación se constituye en una ac- 
ción deliberada sustentada en la creatividad, por lo tanto, amerita voluntad e intencionalidad para percibir y producir valores que prevengan y/o estimulen al otro.

En este sentido, son elocuentes las palabras del Docente Universitario E, quien refiriéndose al contacto con la realidad que ella establece durante sus actividades académicas expuso:

...En las asignaturas yo procuro que ellos reflexionen que hagan análisis crítico de la realidad, que no se queden allí, sino que eso permita que ellos transformen sus mismos espacios y eso es muy difícil porque muchas veces el ser humano, nosotros los seres humanos no estamos, no queremos llevar a cabo transformaciones; entonces pareciera que nos gusta estar como estamos....

En las opiniones de estos docentes universitarios, se denota una cierta apatía a los desafíos de la realidad. Estos, les niegan, a los estudiantes, la pronunciación del mundo, cómo dice el pedagogo brasileño Freire (1987, p. 101), en sus opiniones, he podido detectar, la preeminencia de estilos epistemológicos donde se conjugan tendencias positivistas, enmascaradas con laxas premisas de corte constructivista.

Con ellas, pretenden orientar una formación docente, atendiendo sus gustos y preferencias para ejecutar cierta osmosis social no intencionada a través de reflexiones de hechos no vividos. Para ellos habrá entonces que trazar nuevos senderos e intersticios para comprender lo que no se comprende en la vida cotidiana para re-significar nuevas sensibilidades para que cada uno pueda participar creativamente con mayor claridad su propia vida.

\section{9. ÉTICA DE LA COMPRENSIÓN ANTE LOS TE- MORES DE ENFRENTAR LOS RICOS Y DIVER- SOS DESAFÍOS DURANTE LA FORMACIÓN DO- CENTE}

La ética de la comprensión dice Morín (2000, p. 105), es un arte vivir donde comprendemos de manera desinteresada, sin esperar actitudes recíprocas. Lejos de apuntar al rechazo, esta ética, atiende a la argumentación y a las disidencias; no excusa ni acusa e invita en todo momento a evitar la condena. Comprender las actitudes de las personas en las relaciones humanas, es buscar las raíces, las formas y las manifestaciones que las hacen posible. Es comprender a la persona y su entorno de desarrollo sin asumir conductas de jueces en todas las cosas.

Trataré de explicar este aspecto, interpretando la opinión que tienen los docentes universitarios acerca de ciertas conductas de dejadez, que asumen los docentes en formación, cuando tienen que enfrentar sus responsabilidades académicas. En esta atmósfera, el docente universitario constantemente se está enfrentando a los mecanismos de auto-justificación de los docentes en formación. Al ser consultados al respecto los docentes universitarios, mostraron mucha preocupación, sus sonrisas se desdibujaron de sus rostros al comenzar a opinar al respecto:

\section{Docente Universitario B:}

Ve, ahí yo me torno, como dicen ellos, conductista, no... a veces tomo aire y respiro profundo y les digo todos tenemos compromisos y yo sé que muchos de los que están aquí tienen problemas como tú, pero igual cumplieron; ok. No pudiste esta vez; entonces vamos a hablar...

Docente Universitario C:

Cuando eso ocurre les digo: cuando ustedes vengan así no me digan no lo pude hacer... díganme profesora, tuve un problema ¿̇cuándo puedo entregar el trabajo? Pero no lo hagan para que yo los exonere... porque pretenden... que los exoneren de algunos trabajos. Yo les digo no, vamos a hablar de cuándo me lo puedes entregar.

Docente Universitario D:

...uno se molesta ... como ser humano se molesta... ni siquiera justificación sino mentiras y tú descubres que es una mentira no, y que te engañan ... Uno puede entender la parte humana, no, pero también hay una responsabilidad académica...cuando comienzan...a evadir sus respon- 
sabilidades a mí eso me incomoda muchísimo, y me molesta, me molesta sobre todo porque son docentes ... y sale el poder, ejercicio del poder...

\section{Docente Universitario A:}

...me molesto, me enojo a veces hasta hago evidencia de mi molestia y le llamo la atención, a veces de una manera muy fuerte... va a depender del gran embuste que me hayan metido o de la gran auto-justificación que me hayan hecho... quizá uno las deje pasar una vez, pero que se haga una constante realmente es lo que a mí me incomoda y me molesta...

\section{Docente Universitario E:}

A veces me han molestado tanto que hasta los he aplazado. Entonces, entro en contradicciones, entre hacer lo justo y si no lo hago alcahueteo tanta sinvergüenza, vicios y mañas que tenemos nosotros los humanos.

La realidad es constituida con lo que los seres humanos hacemos. Cualquier declaración o afirmación que se haga de ella, no puede hallarse independientemente de lo que la persona hace. Cuando recurrimos a mentiras y a engaños, para la manipulación de nuestras relaciones interpersonales, somos incapaces de distinguir en la experiencia entre percepción e ilusión.

En las opiniones de estos docentes universitarios, se denota la preocupación que en ellos existe, por el hecho de que los recursos de validación de las explicaciones dadas por los docentes en servicio, los lleve a legitimar con sus conductas, realidades. En este camino explicativo, las elucidaciones suponen la presión de un acceso privilegio a una realidad por parte del que explica. El docente universitario, expresa la negación de su desacuerdo en este camino explicativo, y transforma la pretensión de conocimiento en una demanda de obediencia. Se produce de esta manera una pugna entre dos realidades irreconciliables, por las que las relaciones de exigencias pueden llegar a anular las relaciones de armonía, en las cuales podemos alcanzar a herirnos o acariciarnos con las palabras como lo señala Maturana (2008, p. 23), en sus discusiones acerca del sentido de lo humano.

Del mismo modo, si queremos alcanzar en la relación con el otro, una convivencia estética basada en la armonía, tenemos entonces, que pensar, en un mundo de relaciones humanas definido en pactos, convenios, acuerdos y negociaciones como ejercicio dinámico en cada realidad. Sin embargo, el problema está en creer que uno puede avasallar a los otros, reclamando para sí el privilegio de saber cómo son las cosas en sí; sin darnos cuenta, que cada quien tiene una realidad particular la cual enfrenta con sus carencias y virtudes.

Se explicará esta situación a través de los argumentos expuestos en relación a la actuación de los docentes en formación durante su quehacer universitario, ya referida anteriormente, de los cuales se han extraído las siguientes consideraciones: docentes que tienen que enfrentarse en el día a día a dos y hasta tres trabajos en los tres turnos para completar su carga horaria; tienen que profesionalizarse para lograr su permanencia y mejores remuneraciones una vez insertados en el sistema Educativo; generalmente carecen de hábitos de lectura (en su mayoría), por lo que esta exigencia se les hace pesada y poco atractiva; la mayoría carece de los recursos técnicos necesarios para facilitar el trabajo de investigación o, sencillamente, desconocen los procedimientos de investigación y, para agravar aún más la situación, tienen que ocuparse de las labores domésticas que demandan tiempo y energía.

Todo este mundo de acciones parece vibrar al momento de enfrentar, durante su proceso de formación profesional, cualquier reto innovador; y entonces, la ira, el miedo y la desesperación los invaden; pues, cuando tratan de ampararse en sus mecanismos egocéntricos de auto-justificación, en sus explicaciones cotidianas ante el docente de la universidad no encuentra en él el apoyo necesario para la comprensión de sus necesidades. Obviamente, no puede comprenderlos, porque éste, no ha recorrido el camino escabroso que él está recorriendo. Porque el docente universitario no emprendió su labor académica en la universidad antes de graduarse. El inició sus tareas académicas con un título ya adquirido; es 
cierto que, tiene después que, realizar estudios de postgrado; pero, no en las mismas condiciones que el docente en servicio.

Seyla Benhabib (1990, p. 136), considera "a todos y cada uno de los seres racionales como un individuo con una historia, una identidad y una constitución afectivo-emocional concretas" por lo que les da la denominación del otro concreto. El docente universitario, convertido en el otro concreto, ya ha experimentado hábitos de lectura, ya tiene experiencias para resolver situaciones de aprendizaje; se supone que ya ha adquirido la seguridad para expresarse con un lenguaje oral y escrito coherente y prolífero ante cualquier escenario; y quizás, cuente con los recursos necesarios para costear ayudantes domésticos. Aunado a esto, con los estudiantes sólo los une interacciones institucionales, en su mayoría, carentes de amistad, amor, consideraciones.

Por lo tanto, no se puede estremecer, junto al docente en formación, en esta visión que lo acoge, porque no conoce a plenitud sus carencias, deseos y necesidades; por el contrario, se les imponen con su "presencia sin historia, con su voz sin nombre, con su gesto imperceptible" irrumpiendo la identidad del docente, en su historia en sus sentimientos, (Pérez, 1997, p. 165). Por todo esto, le será cuesta arriba identificarse con sus angustias, de reconocer esas debilidades en sí mismo, por lo que la comprensión intersubjetiva, la armonía y la ternura como expresión de acoger al otro, no tienen cabida en esta relación.

Son dos realidades opuestas que no se pueden comprender y mucho menos el profesor universitario para quien el punto de referencia del ser-hacer docente lo expresa un modelo de docente, que no logra perfilar en el docente en servicio que se está formando. Con estas argumentaciones no estoy avalando tanta irregularidad académica. Lo que quiero expresar, es la necesidad de comprender e identificarse con la vida del otro. Reconozco que, en toda relación humana, la angustia y el sufrimiento forman parte de ella; pero, lo podemos superar, abriendo brechas que permitan la entrada de la generosidad. Más, aún si estamos conscientes de lo difícil que pudiera resultar formar a los seres humanos en la tolerancia, el respeto y la aceptación de las diferencias, en un medio social y cultural preñado de pasiones ideológicas, políticas y sociales que pudieran conducir a dogmatismos excluyentes. Se trata de pensar desde las "imágenes del otro", en tanto, pensamiento que considera las realidades del otro. De lo contrario esta práctica se puede convertir en un círculo vicioso, pues el docente pudiera repetir estas mismas prácticas en su quehacer docente.

Evidentemente, la percepción que se obtiene de una persona en un solo contacto no permite conocer la trama que lo envuelve, el torrente de acontecimientos que nublan su espíritu. Lo que se percibe del otro es tan sólo lo que éste quiere dar a conocer. Y más intenso aun, existen personas que cuando están en público, personifican el modo en que quieren ser vistos $\mathrm{y}$, por lo tanto, considerados, por lo que, pueden proponerse a ser distinto a como son realmente. Esta prerrogativa, demuestra que las circunstancias personales no se perciben a simple vista. Podemos llegar a ser lo que los demás crean de nosotros. Lo que quiero destacar con esto es que, el proceder de la persona, genera sus propios efectos; constituyéndose en una identidad autónoma. Por lo que podemos concluir, que no hay esencia a desvelar sino identidad a construir y en esa construcción liberamos el lenguaje con sus posibilidades creadoras, para alcanzar un entendimiento.

No obstante, es posible aproximarse al conocimiento de la subjetividad de una persona, descubriéndolo en el convivir del día a día, en el lenguaje, en el intercambio intersubjetivo de conciencias durante su participación en el mundo, pero, lo que resulta imposible es llegar a conocer el entresijo que lo caracteriza. Torralba (1998, p. 23) cuando describe los "rasgos de la condición humana" señala en primer lugar al misterio. Explica que la persona es misterio, puesto que ésta no puede ser estudiada de modo empírico a la manera como estudian las ciencias naturales a los organismos vivos para conocer lo que Heidegger llama el misterio del ser. Es decir, eso que permanece en lo más recóndito de su ser, que no es evidente a cualquier análisis extrínseco, epidérmico, fenoménico y que no se agota en su ros- 
tro externo.

Se trata, de aquello que está más allá de lo físico y que no puede ser atrapado ligeramente en un lenguaje conceptual. Este recinto interior, oculta la privacidad más intima de cada ser humano, su esencia, su substancia, su subjetividad, sus sensibilidades; allí, se guardan celosamente recuerdos, vivencias, imágenes, donde solamente la misma persona puede auto-conocerlos. Es en las obras de arte donde las personas exteriorizan y plasman su mundo interior. Lamentablemente, toda persona no cuenta con este don. Tener presente tal situación, hará posible cualquier intento de comprensión humana que se haga para advertir las situaciones de vida que viven los otros.

Dice Morín (2002), que el "conocimiento comprehensivo" es un conocimiento que se basa en la comunicación, en la empatía y simpatías a través del diálogo incansable. No obstante, es necesario tener presente que a pesar de que el diálogo y la palabra permiten la comunión entre dos o más conciencias, siempre van a coexistir situaciones ocultas en cada conciencia que permanecen irrevelables, que no llegan con facilidad a su plena manifestación, porque siempre habrá algo en el prójimo que se desconoce. La alteridad persiste a pesar del diálogo y la convivencia. Lo que acabo de exponer, pudiera no tener sentido para algunos. Evidentemente, no es una novedad ni una invención. Más bien, lo que trato es de hacer hincapié en una situación, quizás, contradictoria, representada en el interés y motivación que expresan los docentes durante su formación al participar en eventos distintos a los establecidos en la cultura académica. Y, en segundo lugar, que el docente se actualice con la realidad; parafraseando a Zubiri (1995, p. 44), se deje poseer por ésta para hacerla suya. Esto, solo es posible apropiándose de la alteridad que la realidad les ofrece como esencia abierta. Esta, en tanto que esencia abierta, desborda sus contenidos dados, abriéndose en una dinámica rebosada que mueve a la inteligencia para que ésta renueve ese dinamismo en el cual ella misma está inmersa. Evidentemente, no se trata, en este trabajo, de asumir la realidad en lo puramente intelectivo, sino articulada con lo que sentimos como seres humanos al sumergirnos en ella.

\section{REFERENCIAS BIBLIOGRÁFICAS}

Derrida, J. (1997). Una filosofía deconstructiva. Zona Erógena, 35, 1-10. Recuperado de http:// goo.gl/6r7XKG

Dilthey, W. (1900). The rise of hermeneutics. Nueva York: New Literary History.

Flórez, R. (1996). Hacia una pedagogía del conocimiento. Colombia: McGraw-Hill.

Freire, P. (1987). Pedagogía del oprimido. Colombia: Siglo Veintiuno Editores.

Gadamer, H. (1991). Verdad y método. Salamanca: Ediciones Sígueme.

Gutiérrez, M. (1999). Inferencias en la comprensión del lenguaje. En F. Cuetos \& M. de Vega (Eds.), Psicolingüística del español (pp. 231270). Madrid: Trotta.

Heidegger, M. (1983). Ser y tiempo. Traducción, prólogo y notas de Jorge Eduardo Rivera. Edición electrónica de www.philosophia.cl / Escuela de Filosofía Universidad ARCIS.

Husserl, E. (1994). Investigaciones lógicas. España: Revista de Occidente.

Lankshear, C., \& Knobel, M. (2003). Problemas asociados con la metodología de la investigación cualitativa. Caracas: Candidus Editores Educativos.

Maffesoli, M. (1997). Elogio de la razón sensible: Una visión intuitiva del mundo contemporáneo. Barcelona: Paidós.

Maturana, H. (2008). El sentido de lo humano. Argentina: Ediciones Granica. S.A. 
Morín, E. (2000). Los siete saberes necesarios a la educación del futuro. Caracas: Editorial IESALC.

Morín, E. (2002). La cabeza bien puesta: Repensar la reforma: Reformar el pensamiento: $\mathrm{Ba}$ ses para una reforma educativa. España: Nueva Visión.

Pérez, N. (1997). “Imágenes del otro: imágenes, tal vez, de una función pedagógica otra". En J. Larrosa \& N. Pérez (Comp.), Imágenes del otro (pp. 163-166). Valencia: Editorial Virus.

Rorty, R. (1996). Objetividad, relativismo y verdad. Barcelona: Paidós.

Schleiermacher, F. (2000). Sobre los diferentes métodos de traducir. Traducción: Valentín García Yebra. Madrid: Editorial Gredos.

Seyla, B. (1990). "El otro generalizado y el otro concreto: la controversia Kohlberg-Gilligan y la teoría feminista". En S. Benhabib \& D. Cornell (Eds.), Teoría feminista y teoría crítica. Valencia: Ediciones Alfons et Magnánim.

Torralba, F. (1998). Pedagogía del sentido. Madrid: PPC.

Valera-Villegas, G. (2002). Pedagogía de la alteridad: Una dialógica del encuentro con el otro. Caracas: Comisión de Estudios de Postgrado. Facultad de Humanidades y Educación. Universidad Central de Venezuela.

Vattimo, G. (1996). Ética de la interpretación. Barcelona: Paidós Estudio S.A.

Wilber, K. (1987). Un Dios sociable. Barcelona: Editorial Cairos.

Zemelman, H. (1992). Los horizontes de la razón. Tomo I y II. México: Editorial Anthropos.

Zubiri, X. (1980). Inteligencia y realidad. Madrid: Alianza.
Zubiri, X. (1995). Estructura dinámica de la realidad. Madrid: Alianza. 